\title{
РАДИОГЕННЫЙ УРАН-234 В СОСТАВЕ ГУМУСОВЫХ КИСЛОТ ГРАПТОЛИТОВОГО АРГИЛЛИТА
}

\author{
Р. В. БОГДАНОВ ${ }^{(a)}$ \\ C. А. ОЗЕРНАЯ ${ }^{(a)}$ \\ А.-Т. А. ПИХЛАК ${ }^{*(\mathrm{~b})}$ \\ C. А. ТИМОФЕЕВ ${ }^{(\mathrm{a})}$ \\ (a) Санкт-Петербургский государст- \\ венный университет, кафедра \\ радиохимии \\ Университетская наб. 7-9, \\ Ст. Петербург \\ 199034 Россия \\ (b) Национальный институт \\ химической и биологической \\ физики Эстонии \\ ул. Акадезмия 21, Таллинн \\ 12818 Эстония
}

\author{
R. BOGDANOV ${ }^{(a)}$ \\ S. OZERNAYA ${ }^{(a)}$ \\ A.-T. PIHLAK ${ }^{*(b)}$ \\ S. TIMOFEEV ${ }^{(a)}$
}

St.-Petersburg State University

Department of radiophysics

7-9 Universitetskaya nab.

St. Petersburg

199034 Russia

National Institute of Chemical Physics and Biophysics

21 Akadeemia St., Tallinn

12812 Estonia

Гумусовые кислоты представляют собой гетерогенные полиароматические соединения, включающие карбоксильные, карбонильные и амино-группы, фенольные гидроксилы, оксихинонные и эфирные группировки, а также некоторые другие функциональные группы [1]. Сложность процессов связывания ионов металлов наглядно отражается в терминах, описывающих ассимиляцию урана гумином, гуминовыми кислотами (ГК) и фульвокислотами (ФК): ассоциация, адсорбция, электростатическое взаимодействие, захват, катионный обмен, комплексообразование, хелатизация [2]. Предположительно, ион $\left(\mathrm{UO}_{2}\right)^{2+}$ образует бидентатные и полидентатные связи с карбоксильными группами гуминовых кислот [3,4], есть и убедительные аргументы в пользу монодентатных комплексов уранила [5].

Вопрос о состоянии радиогенных атомов - членов радиоактивного ряда урана- 238 - в составе гуматов и фульватов еще менее однозначен. Обобщенные в [6] данные о способности различных химических элементов «сорбироваться» на гуминовых кислотах указывают на то, что первый продукт в цепочке альфа-распада урана-238, UX1(Th-234),

\footnotetext{
*Corresponding author: e-mail Pihlak@kbfi.ee
} 
имеет способность к сорбции, превышающую сорбционную способность катиона $\left(\mathrm{UO}_{2}\right)^{2+}$ : «Сорбированные катионы находятся в постоянном обмене с неадсорбированными катионами, находящимися в воде». При этом имеет место конкуренция между ионами металла и водорода. В свете такой трактовки вполне естественно, что избыток изотопа ${ }^{234} \mathrm{U}$ по сравнению с материнским изотопом ${ }^{238} U$ в почвах с высоким содержанием гумуса обычно рассматривается в литературе как результат движения почвенной влаги, обогащенной изотопом ${ }^{234} \mathrm{U}$, и последующего закрепления урана-234 на веществе гумуса [7].

В ходе изучения сложной природной системы, образуемой несколькими типами грунтовых вод местности Горлебен (Северная Германия) [8] были определены изотопные соотношения ${ }^{234} \mathrm{U} /{ }^{238} \mathrm{U}$ и ${ }^{230} \mathrm{Th} /{ }^{234} \mathrm{U}$ для твердой фазы, коллоидной фазы и воды. Оказалось, что коллоиды с размерами 1-1000 нм представлены чаще всего гуминовой кислотой, а органические молекулы, ассоциированные с раствором, были идентифицированы как фульвокислоты. В большинстве случаев изотопное равновесие между указанными фазами отсутствовало. Отношение ${ }^{230} \mathrm{Th} /{ }^{234} \mathrm{U}$ в растворе, то есть в составе ФК, было низким $(<0.1)$, что, по мнению авторов, согласуется с низкой растворимостью тория по сравнению с ураном.

Предположительно, фракция фульвокислоты происходит преимущественно из приповерхностных почвенных слоев, в то время как фракция гуминовой кислоты - в основном из органического вещества более древних осадков, например, образуется при смешении богатой органическим веществом воды и древесного лигнита.

В указанных выше исследованиях явно прослеживается такой ход логических рассуждений: наличие радиогенных атомов в гумусе есть результат взаимодействия органической фазы с радионуклидами, растворенными в природных водах или модельных лабораторных раствоpax. Однако данным аспектом проблема не исчерпывается. Дело в том, что изотоп ${ }^{234} \mathrm{U}$, ассимилированный гумусом наряду с изотопом ${ }^{238} \mathrm{U}$ в древних биогенных породах, например в черных сланцах, полностью распался. Тот уран-234, который присутствует в этих породах в настоящее время, образовался в основном в последние 1,5-2 млн. лет. Встаёт вопрос, сохраняет ли радиогенный уран, как и другие радиогенные нуклиды ряда урана-238, химическую форму гуматов (фульватов) в твердой органической фазе гумуса? Такая постановка вопроса естественна, поскольку в результате альфа-распада радиогенные атомы (или их ближайшие материнские нуклиды) приобретают кинетическую энергию отдачи порядка $10^{5}$ эВ, в результате чего как первоначальные, так и соседние с нею, молекулы, находящиеся в зоне трека атома отдачи, оказываются полностью или частично разрушенными. Возможность же сохранения (или реконструкции?) гуматных (фульватных) комплексов радиогенных атомов в твердой фазе после акта ядерной отдачи не является очевидной. 
Настоящее исследование продолжает серию работ [9-11] и посвящено радиохимическому изучению нуклида ${ }^{234} U$ во фракциях гуминовых и фульвокислот граптолитовых аргиллитов (диктионемовых сланцев) Прибалтийского бассейна. Накопление урана в этих породах связано с ранними стадиями литогенеза и преобразования ОВ; возникновение же собственных минералов урана можно считать результатом более поздних диагенетических и эпигенетических процессов $[12,13]$.

\section{Экспериментальная часть}

Объектом исследования служил диктионемовый сланец, пробы которого отобраны из керна скважины 191-а месторождения на СевероЗападе Эстонии, проба 2304 была взята из нижней четверти пласта, примерно на $(75 \pm 15)$ см выше его подошвы [14]. По данным альфаспектрометрического анализа, отношение активностей (AR) исследуемого образца было следующим: ${ }^{234} \mathrm{U} /{ }^{238} \mathrm{U}=1,03 \pm 0,02$ и ${ }^{230} \mathrm{Th} /{ }^{234} \mathrm{U}=$ $0,99 \pm 0,06$ при среднем содержании урана в пробе $\sim 100$ мкг/г, то есть уран и продукты его распада в сланце находятся в состоянии радиоактивного равновесия или весьма близки к нему.

Общий органический углерод определяли в изучаемом образце по методу Тюрина [15]. Фракционно-групповой состав гумуса анализировали по методике [16].

Схема фракционно-группового анализа гумусового вещества (ГВ) диктионемового сланца на рис. 1 дает возможность подразделить гумусовые вещества на три фракции ГК и четыре фракции ФК.

\section{Гуминовые кислоты}

- Фракция 1 , растворимая непосредственно в 0,1 моль/л $\mathrm{NaOH}$, свободная и связанная с подвижными полуторными оксидами.

- Фракция 2, растворимая в 0,1 моль/л $\mathrm{NaOH}$ после декальцирования почвы и связанная в основном с кальцием.

- Фракция 3, растворимая в 0,02 моль/л $\mathrm{NaOH}$ при 6-часовом нагревании на водяной бане, связанная с глинистыми минералами и устойчивыми полуторными оксидами.

\section{Фульвокислоты}

- Фракция $1 a$, растворимая в 0,1 моль/л $\mathrm{H}_{2} \mathrm{SO}_{4}$ при декальцировании почвы, свободная и связанная с подвижными полуторными оксидами (так называемая “агрессивная” фракция).

- Фракция 1 , растворимая в 0,1 моль/л $\mathrm{NaOH}$ из недекальцированной почвы и связанная в почве с фракцией 1 гуминовых кислот.

- Фракция 2, растворимая в 0,1 моль/л $\mathrm{NaOH}$ только после декальцирования и связанная с фракцией 2 гуминовых кислот. 


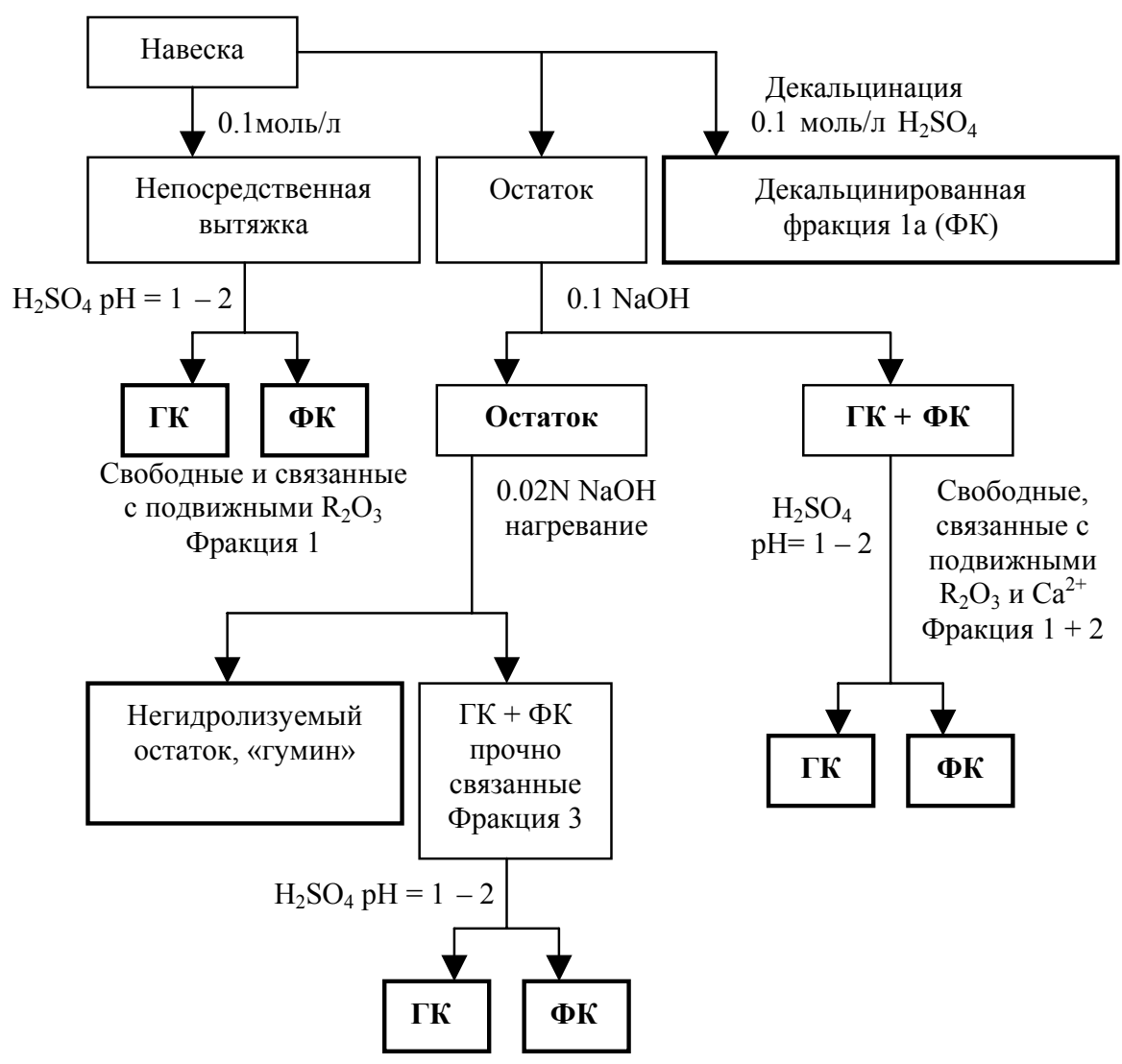

Puc. 1. Схема фракционно-группового анализа гумусового вещества диктионемового сланца.

Fig. 1. Schema of fractional and group analysis of humic matter of Dictyonema shale.

- Фракция 3, растворимая в 0,02 моль/л $\mathrm{NaOH}$ при 6-часовом нагревании на водяной бане и связанная с фракцией 3 гуминовых кислот.

Величина образующегося в ходе анализа нерастворимого остатка гумуса характеризует прочность закрепления гумусовых веществ с глинистыми минералами и степень гумификации органического вещества.

Оптическую плотность гумусовых кислот определяли методом Плотниковой-Пономаревой [17], измеряя на ФЭК и других оптических приборах при синем светофильтре (440 нм). Коэффициент оптической плотности, являющийся информативной характеристикой природы гумусовых кислот, вычислялся по формуле

$$
E=D / C \cdot H,
$$

где $D$ - оптическая плотность раствора; 
$C$ - концентрация углерода, мг/мл;

$H$ - толщина просматриваемого слоя, см.

Для выявления взаимосвязи между изотопами урана и компонентами гумуса были использованы две схемы последовательного извлечения и изоляции органических фракций:

- Схема 1: последовательное воздействие " $\mathrm{H}_{2} \mathrm{O}-\mathrm{NaOH}-\mathrm{HCl}-\mathrm{HNO}_{3}$ ", что позволяет определить корреляцию между изотопами урана и содержанием и составом ГК и ФК в выделенных фракциях.

- Cхема 2: "HCl-NaOH-HNO 3 ", что позволяет оценить поведение изотопов урана как результат декальцинации обеих гумусовых кислот или, в более широком смысле, в процессе кислотного извлечения ионов металлов из $\mathrm{OB}$, если при этом включать в рассмотрение кероген.

В экспериментах использовались образцы, измельченные до размера зерен менее 0,25 мм. Все щелочные и кислотные вытяжки выполнялись при комнатной температуре. Таблица 1 иллюстрирует фрагменты обеих схем с указанием метода извлечения и осаждения соответствующей органической фракции. Декальцинацию выполняли растворами $\mathrm{HCl}$ различной концентрации. Щелочные вытяжки для выделения соответствующих фракций гумусовых кислот обрабатывали по схеме, представленной на рис. 2. Нерастворимый в кислотах и щелочах кероген переводили в раствор путем сжигания и кислотного разложения остатка при длительном нагревании в смеси $\mathrm{HF}$ и $\mathrm{HNO}_{3}$.

Таблииа 1. Последовательность химических воздействий на две пробы диктионемового сланца

Table 1. Sequence of chemical actions on two samples of Dictyonema shale

\section{Схема № 1, навеска 15 г}

- Дистиллированная вода, 5 суток 1 моль/л $\mathrm{NaOH}, 1$ сутки

- 1 моль/л $\mathrm{NaOH}, 1$ сутки

- 1 моль/л $\mathrm{NaOH}, 5$ суток

- 0,05 моль/л HCl, 30 минут

- 1 моль/л $\mathrm{HCl}, 30$ минут

- 6 моль/л $\mathrm{HCl}, 30$ минут

- 11 моль/л $\mathrm{HCl}$, сутки

- 11 моль/л $\mathrm{HCl}$, сутки

- 11 моль,л $\mathrm{HCl}$, сутки

- $\mathrm{HNO}_{3}$ (конц.), 3 часа

- $\mathrm{HNO}_{3}$ (конц.), 3 суток

- $\mathrm{HF}(1: 1), 2$ суток

- $\quad$ Отжиг и разложение остатка
Схема № 2, навеска 20 г

- $\quad 0,05$ моль/л $\mathrm{HCl}, 30$ минут

- 1 моль/л $\mathrm{HCl}, 30$ минут

- 6 моль/л $\mathrm{HCl}, 30$ минут

- 11 моль/л $\mathrm{HCl}$, сутки

- 11 моль/л $\mathrm{HCl}$, сутки

- 11 моль/л $\mathrm{HCl}$, сутки

- 1 моль/л $\mathrm{NaOH}$, сутки

- 1 моль/л $\mathrm{NaOH}$, сутки

- 1 моль/л $\mathrm{NaOH}, 5$ суток

- $\mathrm{HNO}_{3}$ (конц.), 3 часа

- $\mathrm{HNO}_{3}$ (конц.), 3 суток

- $\operatorname{HF}(1: 1), 2$ суток

- Отжиг и разложение остатка 


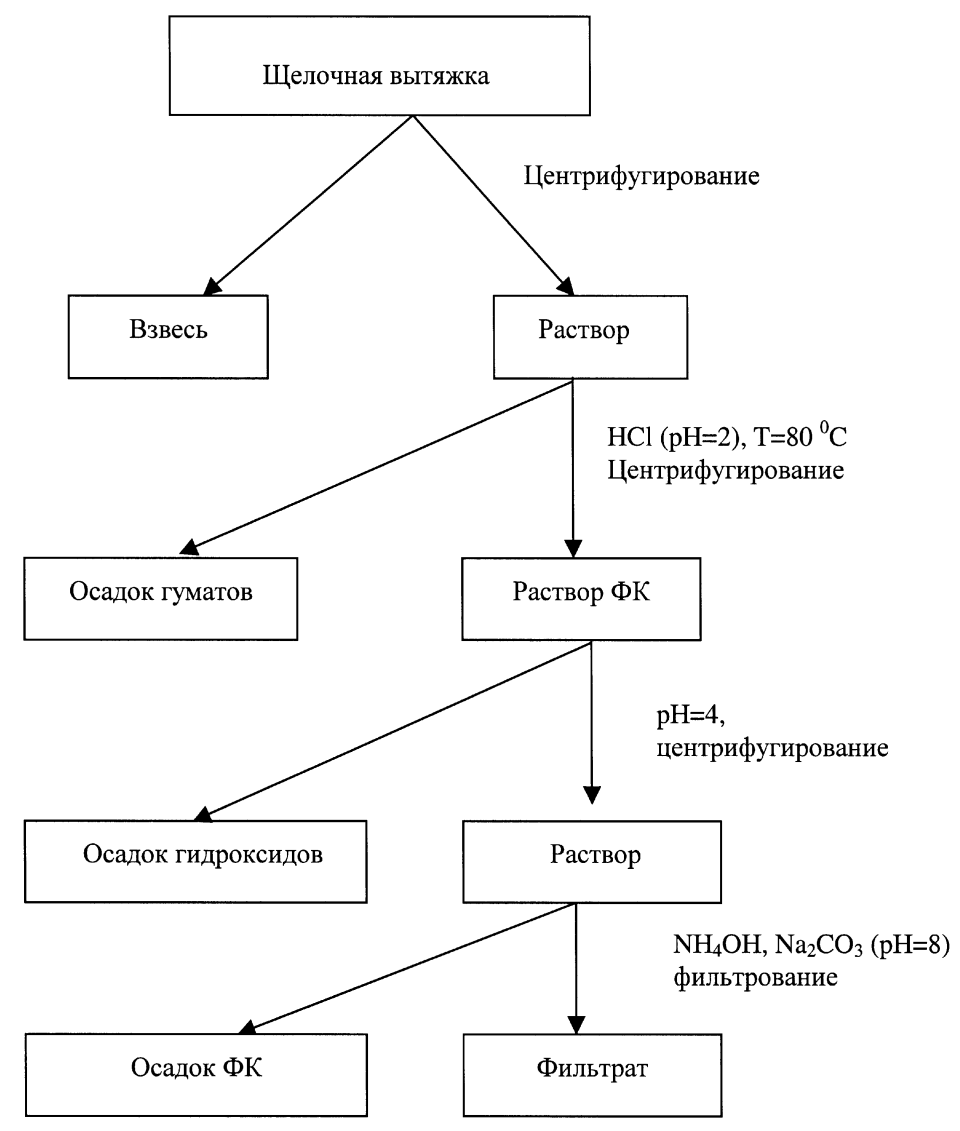

Рис. 2. Химические фракции, выделяемые из щелочных вытяжек

Fig. 2. Chemical fractions separated from alkaline extracts

Выделение и концентрирование урана из соответствующих химических фракций проводили по методике, предложенной в работе [9]. Альфа-источники приготовляли методом электролиза [18].

Альфа-излучение полученных источников регистрировали на спектрометрах с поверхностно-барьерерными $\mathrm{Si}(\mathrm{Au})$-детекторами и 4096-канальным анализатором АИ-1024-95. Данные альфа-спектроскопии поступали в компьютер и обрабатывались по программе [19]. Погрешности величин AR соответствуют доверительной вероятности 0.68 .

\section{Результаты и обсуждение}

\section{Характеристика органического вещества диктионемового сланца}

Судя по фракционно-групповому составу гумуса и оптической плотности его фракций (таблицы 2 и 3 ), в изученном образце сланца содержится $14,4 \%$ органического углерода, однако только $0,26 \%$ его (то есть 
0,018 от общего количества ОВ сланца) связано с ГК и ФК, то есть с собственно гумусовыми кислотами. Остальная часть ОВ $(98,2 \%)$ представлена гуминами - нерастворимыми в условиях стандартного анализа гумусовыми веществами, и трудно окисляемыми веществами индивидуальной природы, составляющими ОВ керогена.

Таблица 2. Фракционно-групповой состав гумуса Table 2. Fraction and group composition of humus

\begin{tabular}{|c|c|c|c|c|c|c|c|c|c|c|c|}
\hline \multirow{2}{*}{$\begin{array}{c}\mathrm{C}_{\mathrm{opr}}, \\
\%\end{array}$} & \multicolumn{4}{|c|}{ Гуминовые кислоты } & \multicolumn{5}{|c|}{ Фульвокислоты } & \multirow{2}{*}{$\begin{array}{c}\text { Сумма } \\
\text { ГВ }\end{array}$} & \multirow[t]{2}{*}{ ГК/ФК } \\
\hline & 1 & 2 & 3 & Сумма & $1 \mathrm{a}$ & 1 & 2 & 3 & Сумма & & \\
\hline \multirow[t]{2}{*}{14.40} & $\underline{0.02}$ & $\underline{0.03}$ & $\underline{0.06}$ & $\underline{0.11}$ & $\underline{0.04}$ & $\underline{0.04}$ & $\underline{0.02}$ & $\underline{0.05}$ & $\underline{0.15}$ & $\underline{0.26}$ & \multirow[t]{2}{*}{0.73} \\
\hline & 0.14 & 0.21 & 0.42 & 0.77 & 0.28 & 0.28 & 0.14 & 0.35 & 1.05 & 1.81 & \\
\hline
\end{tabular}

Примечание: в числителе - \% к породе; в знаменателе - \% к $\mathrm{C}_{\text {орг }}$.

Таблица 3. Коэффициент оптической плотности гумусовых кислот $(\lambda=440$ нм $)$

Table 3. Coefficient of optical density of humus acids $(\lambda=\mathbf{4 4 0} \mathbf{~ m m})$

\begin{tabular}{|c|c|c|c|c|c|}
\hline $\begin{array}{c}\text { Непосредственная } \\
0.1 \text { М NaOH } \\
\text { вытяжка: } \\
\text { ГК1 + ФК1а + ФК1 }\end{array}$ & ГК1 & ФК1a + ФК1 & $\begin{array}{c}0.1 \text { М NaОН вытяжка } \\
\text { после декальцирования: } \\
\text { ГК1 + ФК1а + ФК1 + ГК } 2+ \\
\text { ФК } 2\end{array}$ & $\begin{array}{c}\text { ГК1 + } \\
\text { ГК2 }\end{array}$ & $\Phi К 2$ \\
\hline 3.4 & 7.0 & 3.0 & 3.6 & 8.6 & 3.1 \\
\hline
\end{tabular}

Гумусовые кислоты представлены тремя фракциями гуминовых кислот и четырьмя фракциями фульвокислот. Гуминовые кислоты исследуемого сланца относятся к группе бурых гуминовых кислот, характеризующихся слабой способностью растворяться в воде и химическим сродством к полуторным оксидам, особенно к оксидам железа, с которыми они образуют устойчивые комплексные соединения. С кальцием и другими двухвалентными катионами они взаимодействуют слабо и легко отдают их в раствор под действием воды.

В составе гумуса доминируют фракции 3 обоих типов гумусовых кислот, то есть тесно связанных с глинистыми минералами и устойчивыми полуторными оксидами. Это свидетельствует об очень прочном закреплении гумусовых веществ минеральной частью сланца и органоминеральной природе ОВ. Следует также отметить преобладание в гумусе ФК над ГК: отношение концентраций $\mathrm{C}_{\text {гк }} / \mathrm{C}_{\phi к}=0,73$. Коэффициенты оптической плотности ФК составляют 3,0-3,1 и ГК 7,0-8.6 (коэффициент оптической плотности у молодых ГК равен $\sim 4$ ). Такие величины - признак принадлежности изучаемого ОВ к классу гуму- 
совых кислот и их химической “зрелости”. Это позволяет отвергнуть гипотезу о том, что выделенные кислоты образовались в результате окисления керогена после извлечения сланца из буровой скважины и последующего хранения пробы.

Из данных таблицы 4 видно, что более жесткая по сравнению со стандартной методикой процедура обработки проб не меняет природы выделяемых ФК, о чем свидетельствуют значения оптической плотности $3,0 \pm 0,1$. Применение 1 моль/л $\mathrm{NaOH}$ и, особенно, повторная обработка образца способствуют извлечению более гумифицированных соединений, отличающихся более высокой степенью ароматизации, о чем свидетельствует возрастание коэффициента оптической плотности

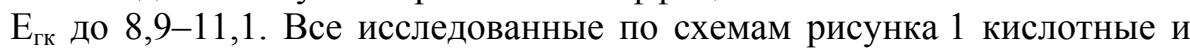
щелочные вытяжки содержат гумусовые кислоты: кислотные вытяжки содержат ФК, щелочные вытяжки содержат ГК и ФК. В ряду щелочных вытяжек максимальное количество ГК переходит после предварительной обработки пробы соляной кислотой (фракция S9/5-6).

Таблица 4. Содержание ГК $\left(\mathbf{C}_{г \kappa}\right)$ и ФК $\left(\mathbf{C}_{\text {фк }}\right)$ в щелочных вытяжках и оптическая плотность соответствующих растворов $\left(E_{\text {гк }}\right.$ и $\left.E_{\phi к}\right)$

Table 4. Content of humic and fulvic acids in alkaline extracts, and optical density of corresponding solutions

\begin{tabular}{|l|l|c|c|c|c|c|c|}
\hline Фракция & \multicolumn{1}{|c|}{ Вытяжка } & $\begin{array}{c}\mathrm{C}_{\text {гк }}, \\
\text { \% к породе }\end{array}$ & $\begin{array}{c}\mathrm{C}_{\text {гк }}, \\
\text { мг/л }\end{array}$ & $\mathrm{E}_{\text {гк }}$ & $\begin{array}{c}\mathrm{C}_{\text {фк }}, \\
\text { \% к породе }\end{array}$ & $\begin{array}{c}\mathrm{C}_{\text {фк, }} \\
\text { мг/л }\end{array}$ & $\mathrm{E}_{\text {фк }}$ \\
\hline $\mathrm{S} 9 / 5-3-1$ & 1-я NaOH & 0.034 & 57 & 8.9 & 0.216 & 158 & 3.1 \\
$\mathrm{~S} 9 / 5-4-1$ & 2-я NaOH & 0.014 & 22.3 & 11.1 & 0.123 & 89.3 & 2.9 \\
S9/5-6 & $\mathrm{NaOH} \mathrm{после}$ & 0.152 & 101.1 & - & - & - & - \\
& $\mathrm{HCl}$ & & & & & & \\
\hline
\end{tabular}

\section{Изотопный состав и содержание урана в вытяжках из граптолитового аргиллита}

Величины AR и относительные содержания урана (\%) в последовательных вытяжках растворами 1 моль/л $\mathrm{NaOH}$ из двух проб диктионемового сланца в зависимости от процедуры декальцинации проб растворами соляной кислоты - до или после щелочной экстракции гумусовых кислот - приведены в таблице 5. Видно (столбец 3), что в результате трехкратных вытяжек из сланца в щелочные растворы переходит более $30 \%$ содержащегося в нем урана, при этом в ГК его обнаруживается $20,2 \%$ и в ФК 10,56\%. Это осаждение нельзя приписать адсорбции, окклюзии или какому-либо иному механизму захвата урана из раствора. Как правило, доказательством тому служит различный изотопный состав урана в выделенных фракциях. Переход урана в осадок указывает на образование химических соединений этого элемента с соответствующими лигандами уже в фазе гумуса диктионемового сланца. 
Таблица 5. Данные альфа-спектрометрического анализа фракций урана, выделенного в соответствии со схемами 1 и 2 (табл. 1)

Table 5. Alpha-ray spectrometric analysis of uranium fractions extracted according to the schemas 1 and 2 (Table 1)

\begin{tabular}{|c|c|c|c|c|}
\hline \multirow[b]{3}{*}{1} & \multicolumn{2}{|c|}{$\begin{array}{c}\text { Вытяжки } \\
\text { до воздействия } \mathrm{HCl}, \\
\text { схема } 1\end{array}$} & \multicolumn{2}{|c|}{$\begin{array}{c}\text { Вытяжки } \\
\text { после воздействия } \mathrm{HCl} \text {, } \\
\text { схема } 2\end{array}$} \\
\hline & $\begin{array}{c}\text { Выход } \\
\%\end{array}$ & $\begin{array}{c}\mathrm{AR}^{234} \mathrm{U}^{238} \mathrm{U}, \\
\text { Бк/БК }\end{array}$ & $\begin{array}{c}\text { Выход }{ }^{238} \mathrm{U}, \\
\%\end{array}$ & $\begin{array}{c}\mathrm{AR}^{234} \mathrm{U}^{238} \mathrm{U}, \\
\text { БК/БК }\end{array}$ \\
\hline & 2 & 3 & 4 & 5 \\
\hline \multicolumn{5}{|c|}{$\mathrm{H}_{2} \mathrm{O}, 5$ суток } \\
\hline Взвесь & 0.35 & $1.05 \pm 0.10$ & - & - \\
\hline Раствор & 5.4 & $1.47 \pm 0.02$ & - & - \\
\hline \multicolumn{5}{|c|}{$1_{\text {моль }} /$ л $\mathrm{NaOH}, 1$ сутки } \\
\hline Взвесь & 0.7 & $1.03 \pm 0.04$ & 0.8 & $0.48 \pm 0.02$ \\
\hline$\overline{\Gamma K}$ & 6.25 & $1.47 \pm 0.02$ & 1.2 & $0.37 \pm 0.01$ \\
\hline$\Phi$ ФК & 8.32 & $1.11 \pm 0.05$ & 0.69 & $0.53 \pm 0.03$ \\
\hline \multicolumn{5}{|c|}{1 моль/л $\mathrm{NaOH}, 1$ сутки } \\
\hline Взвесь & 1.6 & $1.18 \pm 0.04$ & 0.5 & $0.81 \pm 0.02$ \\
\hline ГК & 5.75 & $1.07 \pm 0.09$ & 0.65 & $0.86 \pm 0.04$ \\
\hline$\Phi$ ФК & 1.9 & $1.45 \pm 0.02$ & 0.2 & $0.98 \pm 0.05$ \\
\hline \multicolumn{5}{|c|}{1 моль/л $\mathrm{NaOH}, 5$ суток } \\
\hline Взвесь & 4.4 & $0.76 \pm 0.06$ & 0.1 & $1.14 \pm 0.07$ \\
\hline ГК & 8.2 & $0.84 \pm 0.03$ & 0.16 & $0.85 \pm 0.06$ \\
\hline$\Phi K$ & 0.34 & $1.21 \pm 0.04$ & 0.16 & $0.82 \pm 0.05$ \\
\hline Растворы & После шести & тадий HCl & После трех с & адий $\mathrm{NaOH}$ \\
\hline \multicolumn{5}{|c|}{3 час, 12 моль/л $\mathrm{HNO}_{3}$} \\
\hline & 6.8 & $0.19 \pm 0.01$ & 2.5 & $2.19 \pm 0.03$ \\
\hline \multicolumn{5}{|c|}{3 сут., 12 моль/л $\mathrm{HNO}_{3}$} \\
\hline & 4.2 & $0.32 \pm 0.01$ & 0.1 & $0.73 \pm 0.03$ \\
\hline \multicolumn{5}{|c|}{2 суток НF (1:1) } \\
\hline & 11.6 & $1.76 \pm 0.02$ & 0.1 & $1.23 \pm 0.04$ \\
\hline Остаток (разложение) & 4.3 & $1.61 \pm 0.02$ & 1.05 & $2.11 \pm 0.05$ \\
\hline
\end{tabular}

Присутствие радиогенного урана в составе гумусовых кислот свидетельствует о том, что несмотря на значительную деструкцию ОВ в треке атома отдачи, не только воссоздается молекула гумусовой кислоты из фрагментов и радикалов, но и возникают достаточно прочные связи урана-234 как с ГК, так и с ФК, позволяющие радиогенному урану следовать за соответствующей органической кислотой при щелочной экстракции и процедуре осаждения.

То, что значение отношения ${ }^{234} U /{ }^{238} U$ в составе органических фаз превосходит единицу, при общем радиоактивном равновесии в ряду урана в изучаемом сланце, указывает на присутствие богатой ураном 
фазы, предположительно урановой черни, находящейся в непосредственном контакте с органическими фазами сланца. Ранее размеры зерен этой оксидной фазы были оценены в $25-35$ нм, а отношение ${ }^{234} U /{ }^{238} U$ в ней в 0,22-0,25 [20]. Возникающие в оксиде при распаде урана-238 атомы отдачи Th-234(U-234) с кинетической энергией 7,2 $10^{4}$ эВ внедряются в органическую фазу и ассимилируются молекулами гумусовых кислот и гумином. Хотя в составе гумуса изучаемого сланца преобладают фульвокислоты (отношение содержаний $\Phi К / Г К=1.37$ ), с экстрагируемыми щелочью гуминовыми кислотами ассоциируется в два раза больше урана-238, чем с фульвокислотами.

Закономерен вопрос: равноценны ли с химической точки зрения оба изотопа урана в составе гумуса? Информацию об этом можно получить из результатов воздействия на сланец растворов соляной кислоты. Изотопный состав соответствующих соляно-кислых экстрактов приводится в таблице 6 . Кратковременное (30 мин) и относительно мягкое воздействие соляной кислотой перед серией щелочных вытяжек даёт значения $\mathrm{AR}>1$ (столбец 3 в табл. 6). Сопоставление этих результатов с величинами AR для последующих, значительно обедненных радиогенным ураном, щелочных вытяжек в схеме 2 (столбец 6 в табл. 5) свидетельствует о том, что органическое вещество является основным источником радиогенного урана для указанных трех кислотных вытяжек.

Таблица 6. Содержание и изотопный состав урана в соляно-кислых вытяжках, полученных по схемам № 1 и № 2

Table 6. Content and isotope composition of uranium in hydrochloric extracts obtained according to the schemas 1 and 2

\begin{tabular}{|c|c|c|c|c|}
\hline $\begin{array}{c}\text { Концентрация } \mathrm{HCl} \\
\text { и длительность } \\
\text { обработки }\end{array}$ & \multicolumn{2}{|c|}{$\begin{array}{c}\text { Воздействие } \mathrm{HCl} \\
\text { до щелочной вытяжки } \\
\text { схема 2 }\end{array}$} & \multicolumn{2}{c|}{$\begin{array}{c}\text { Воздействие } \mathrm{HCl} \\
\text { после щелочной вытяжки } \\
\text { схема 1 }\end{array}$} \\
\cline { 2 - 5 } & $\begin{array}{c}\text { Выход }{ }^{238} \mathrm{U}, \\
\%\end{array}$ & $\begin{array}{c}{ }^{234} \mathrm{U} /{ }^{238} \mathrm{U}, \\
\text { Бк/Бк }\end{array}$ & $\begin{array}{c}\text { Выход } \\
{ }^{238} \mathrm{U}, \%\end{array}$ & $\begin{array}{c}{ }^{234} \mathrm{U} /{ }^{238} \mathrm{U}, \\
\text { Бк/Бк }\end{array}$ \\
\hline 1 & 2 & 3 & 4 & 5 \\
\hline 0.05 моль/л, 30минут & 10.2 & $1.44 \pm 0.01$ & 3.8 & $0.77 \pm 0.02$ \\
1.0 моль/л, 30 минут & 15.4 & $1.43 \pm 0.01$ & 1.8 & $0.38 \pm 0.02$ \\
6.0 моль/л, 30 минут & 23.6 & $1.18 \pm 0.03$ & 4.4 & $0.41 \pm 0.02$ \\
11.3 моль/л, 1 сутки & 18.8 & $0.55 \pm 0.01$ & 9.3 & $0.34 \pm 0.02$ \\
11.3 моль/л, 1 сутки & 8.4 & $0.36 \pm 0.01$ & 4.6 & $0.25 \pm 0.02$ \\
11.3 моль/л, 1 сутки & 14.9 & $0.57 \pm 0.01$ & 4.7 & $0.22 \pm 0.02$ \\
Всего & 91.3 & & 28.6 & \\
\hline
\end{tabular}

В трех следующих соляно-кислых экстрактах (столбец 3 в табл. 5) наблюдается резкое уменьшение значений $\mathrm{AR}$, что вполне очевидно определяется не возрастанием содержания изотопа ${ }^{238} \mathrm{U}$ (столбец 2 в табл. 5), а дефицитом изотопа ${ }^{234} \mathrm{U}$. Следовательно, длительные воз- 
действия концентрированной соляной кислотой подключают к растворению дополнительный источник урана в сланце, а именно тонкую оксидную пленку, характеризующуюся, как упоминалось выше, значением $\mathrm{AR}=0,22-0,25$. Под влиянием этого источника урана значения $\mathrm{AR}$ для этих соляно-кислых фракций скачком опускаются до 0,55 и ниже, хотя все же влияние гумусовых кислот на получаемые в этих фракциях величины AR еще ощущается. В случае, когда органические кислоты полностью или в значительной степени были экстрагированы щелочными растворами (в соответствии со схемой 1), содержание урана-238 в кислотных вытяжках понижается с 91,3 до $28,6 \%$, а значения $\operatorname{AR}(0,22-0,25)$ в точности отражают соотношение изотопов урана в фазе урановой черни (столбец 5 в табл. 6).

Заслуживающим внимание фактом является изменение содержания урана и значений AR во фракциях гумусовых кислот в щелочных вытяжках, полученных после предварительного воздействия соляной кислоты. Легко оценить, что в составе гуминовых кислот, выделяемых по схеме 2 , содержание изотопа ${ }^{238} U$ уменьшилось в 10,04 раза, а во фракции фульвокислот в 10,05 раза (табл. 5) по сравнению с соответствующими величинами для схемы 1. (По-видимому, практическое совпадение этих значений свидетельствует об одинаковом механизме высвобождения урана из фульватных и гуматных комплексов под действием концентрированной соляной кислоты). Для изотопа ${ }^{234} \mathrm{U}$ эти показатели соответственно составляет 19,2 и 15,2 раза. Таким образом, радиогенный уран в полтора-два раза слабее удерживается молекулами гумусовых кислот по сравнению с материнским ураном, что указывает на различный характер или различное количество химических связей, реализуемых обоими изотопами урана.

Можно предположить: либо в химических связях двух изотопов задействованы различные функциональные группы гумусовых кислот, либо изотоп ${ }^{238} \mathrm{U}$ с большей вероятностью образует бидентатные комплексы, тогда как ${ }^{234} \mathrm{U}$ - монодентатные. Согласно [4], существует два вида связывания между катионами металла и гуминовыми анионами, а именно - слабое и сильное связывание, определяемое длительностью контакта металла и гуминовой кислоты. Слабое комплексообразование является результатом связывания катионов металла поверхностными функциональными группами молекулы кислоты. С увеличением времени контакта гуматный полианион имеет время для пространственного сжатия, одновременно катионы металла могут мигрировать к внутренним, менее лабильным функциональным группам. Эти два фактора - миграция металла и «свертывание» гуматных лигандов - в сумме приводят к увеличению доли сильно связанного металла. Предполагается [4], что места более сильного связывания отвечают полидентатным связям.

Понятно, что описанная модель применима к жидкой фазе. Стерические и кинетические препятствия, возникающие при реализации 
подобного механизма в твердой фазе, не позволяют безоговорочно распространить указанные закономерности на твердое органическое вещество диктионемового сланца. Для объяснения различий в поведении четных изотопов урана в гумусовых кислотах следует, по нашему мнению, дополнительно привлечь данные о валентном состоянии (степени окисления) изотопов урана в составе гумуса, которые могут пролить определенный свет на затронутую проблему. Известно, что прочность гуматных и фульватных комплексов $\mathrm{U}^{4+}$ (как и $\mathrm{Th}^{4+}$ ) существенно выше, чем для $\left[\mathrm{UO}_{2}\right]^{2+}[21]$. Поэтому в данном контексте вопрос может сводиться к изучению распределения обоих изотопов по валентным формам. Вполне понятно, что при равновесном соотношении изотопов урана во фракциях U(IV) и U(VI) декальцинация будет протекать (при прочих равных условиях) одинаково для обоих изотопов урана. В работе [22] было показано, что, несмотря на высокое содержание органического вещества, радиогенный уран в диктионемовых сланцах не проявляет тенденции к восстановлению. Более того, радиогенным ураном до значений $\mathrm{AR}=1,25$ обогащается фракция шестивалентного урана, содержание которой составляет $60 \%$. Этот результат отчасти объясняет различную химическую связь материнского и радиогенного урана в гумусовых кислотах, хотя и не исключает влияние других факторов.

Различие в прочности связи между гуминовыми кислотами и изотопами урана ${ }^{238} \mathrm{U}$ и ${ }^{235} \mathrm{U}$ отмечалось в работе [23] (уран-235 использовался в качестве трассера). При объяснении наблюдаемых эффектов авторы отвели большую роль фактору длительности контакта изотопов урана и гуминовых кислот: сотни лет для урана- 238 и короткое время эксперимента для урана-235. Отмечалось, что при увеличении времени контакта трассера с гуминовыми кислотами различие между изотопами нивелируется. Объяснение, по мнению авторов [23], заключается в том, что вслед за быстрым процессом сорбции происходят медленные изменения в состоянии урана, определяемые либо агрегацией макромолекул гуминовых кислот под действием катионов урана, либо, согласно [4], постепенным переходом урана от неспецифической “поверхностной” ассоциации к специфическим местам связывания металла.

Понятно, что временной фактор не является первостепенным для радиогенного урана, поскольку среднее время жизни изотопа ${ }^{234} \mathrm{U}$ составляет 355900 лет. Причина, скорее, в различных стерических и структурных ограничениях, определяющих взаимодействие урана-234 и гумусовых кислот в твердой фазе.

В отношении вещества керогена картина иная. Гумину диктионемового сланца можно приписать отношение ${ }^{234} \mathrm{U} /{ }^{238} \mathrm{U} 1,6-1,7$ или даже 2,1 (нижняя строка в табл. 5,). Согласно [2], фракция гумина состоит из конденсированных геополимерных «протокерогенов» с высоким молекулярным весом. Несмотря на жесткую обработку концентрированными кислотами и щелочью, гумин может содержать ощутимые коли- 
чества урана, который находится в «сильно связывающих центрах». Судя по данным таблицы 5 , можно предположить, что радиогенный уран связан с этими полимерами не менее сильно, чем материнский, и не проявляет тенденции к декальцинации. Мы предполагаем, что причина этого кроется в тесной связи гумина с глинистыми минералами «матрицы» диктионемового сланца и в стабилизации некоторой доли атомов отдачи U-234 в этой сложной системе в четырехвалентном состоянии.

\section{Заключение}

Проведённый химический и радиохимический анализ фракций гуминовой и фульвовых кислот, выделенных из граптолитового аргиллита, позволяет сделать следующие выводы:

1) Разрушенные в результате ядерного распада урана (и других нуклидов) молекулы гумусовых кислот обладают, по-видимому, значительной способностью к реконструкции исходной или идентичной структур в составе ОВ сланца; предположение об участии в реакциях с металлами более мелких структурных фрагментов не подтверждается результатами фракционно-группового анализа гумуса.

2) Радиогенный уран вступает во взаимодействие с функциональными группами гумусовых кислот в твердой фазе, образуя соответствующие химические соединения (гуматы урана).

3) Химическая связь радиогенного урана в составе гуматного комплекса менее прочна, чем у материнского изотопа; одной из причин этого может быть различие в валентном состоянии изотопов урана.

4) По прочности связей атома урана с гумусовами кислотами можно предложить следующую градацию:

- наименее прочные комплексы образуют уранильные ионы при их кратковременном взаимодействии с гумусовыми кислотами в жидкой фазе;

- более прочные соединения дает радиогенный уран(VI) в твердой фазе ОВ сланца;

- еще более прочными связями характеризуются гуматные и фульватные комплексы, образуемые уранильным ионом материнского изотопа ${ }^{238} \mathrm{U}$ в твердой фазе;

- наиболее прочные комплексы образует четырехвалентный уран, особенно в тесной ассоциации гумина и глинистых минералов. 


\section{Благодарность}

Авторы выражают благодарность Н. Е. Орловой за помощь в проведении анализа органического вещества диктионемового сланца.

\section{RADIOGENIC URANIUM-234 IN HUMUS ACIDS OF GRAPTOLITIC ARGILLITE}

\section{R. BOGDANOV, S. OZERNAYA, A.-T. PIHLAK, S. TIMOFEEV}

\section{Summary}

Humates and fulvates of uranium and thorium representing a form of actinide transfer in the environment have been investigated thoroughly enough. Nevertheless, formation of humates (fulvates) of radiogenic nuclides after the preceding high-energy act of nuclear recoil is studied quite insufficiently. This is because isotope ${ }^{234} \mathrm{U}$ assimilated by humus alongside with isotope ${ }^{238} \mathrm{U}$ in ancient biogenic rocks, e.g. black shales, is completely decomposed, while uranium-234 present in these rocks now has formed mainly during the last 1.5-2 million years. The question is: do radiogenic uranium and also other radiogenic nuclides of the uranium-238 series preserve the chemical form of humates (fulvates) in the solid organic phase of humus? Such a question is quite natural: as a result of alpha decay radiogenic atoms (or their nearest parent nuclides) obtain kinetic energy of recoil of the order of $10^{5} \mathrm{eV}$, which leads to full or partial destruction of both the initial molecule and the neighbouring ones in the track of the recoil atom. The possibility to maintain (or reconstruct) humate (fulvate) complexes of radiogenic atoms in the solid phase after the act of nuclear recoil is not obvious.

In the present work, graptolitic argillite (Dictyonema shale) taken from the core of borehole 191-a at a deposit in North-West Estonia was investigated. The sample 2304 was taken from the bottom quarter of the layer, approximately $75( \pm 15) \mathrm{cm}$ above its bottom. Alpha-ray spectrometric analysis data of the sample in question show the following activity ratios (AR) in the investigated sample: ${ }^{234} \mathrm{U} /{ }^{238} \mathrm{U}=1.03 \pm 0.02$ and ${ }^{230} \mathrm{Th} /{ }^{234} \mathrm{U}=$ $0.99 \pm 0.06$, the average uranium content being $\sim 100 \mu \mathrm{g} / \mathrm{g}$. These values suggest that uranium and its decomposition products present in the shale are in the state of radioactive equilibrium or rather close to it.

In the investigated sample, the total content of organic carbon (by Tjurin method) and fraction and group composition of humus (by PlotnikovPonomarjov method) were determined. It was established that the shale sample contains $14.4 \%$ organic carbon, but only $0.26 \%$ of this amount (i.e. $0.018 \%$ of the total organic matter of shale) is related to humic and fulvic acids, in other words to humus acids themselves. The rest of organic matter 
(98.2\%) is presented by humins insoluble in the conditions of standard analysis, and also by individual substances oxidizing with difficulty, which represent components of kerogen organic matter. Humus acids are presented by three fractions of humic acids and four fractions of fulvic acids.

In humic and fulvic acids ${ }^{238} \mathrm{U}$ and ${ }^{234} \mathrm{U}$ content was determined. The influence of decalcination of humates and fulvates on isotopic composition of uranium was studied. After triple extractions, more than $30 \%$ of uranium present in shale is transferred into alkaline solutions. Its distribution is as follows: $20.2 \%$ in humic acids and $10.56 \%$ in fulvic ones. This sedimentation is not attributable to adsorption, occlusion or any other mechanism of uranium capture from a solution as proved by differing isotopic composition of uranium in the separated fractions. Uranium transfer into the deposit definitely proves the formation of chemical compounds of uranium with corresponding ligands in the humus phase of Dictyonema shale. The presence of radiogenic uranium in humic acids proves that, despite of significant destruction of organic matter in the track of the recoil atom, not only the molecule of humic acid is recreated from fragments and radicals, but also strong links of uranium-234 with both humic acids and fulvic acids form. They allow radiogenic uranium to follow a corresponding organic acid at alkaline extraction and sedimentation.

On the background of common radioactive equilibrium in the uranium series in the studied shale, an increase in the value of ${ }^{234} \mathrm{U} /{ }^{238} \mathrm{U}$ ratio in organic phases over unity indicates the presence of an uranium-rich matter. Presumably, it is uranium black which directly reacts with organic phases of shale. The grains of this oxide phase were rated to be of $25-35 \mathrm{~nm}$, and their ${ }^{234} \mathrm{U} /{ }^{238} \mathrm{U}$ ratios within $0.22-0.25$ [20]. Although fulvic acids prevail in the humus of the shale studied (the ratio of fulvic acids to humic ones is 1.37), the amount of uranium-238 associated with humic acids extracted by alkali is twice more than that in fulvic acids. However, uranium in fulvic acids is enriched with radiogenic uranium: the average value of AR for three consecutive alkaline extracts makes $1.17 \pm .03$ for fulvic acids and $1.08 \pm 0.03$ for humic acids. Obviously, it is related to higher content of isotope ${ }^{238} \mathrm{U}$ in humic acids.

Experiments on decalcination of uranium humates and fulfates by hydrochloric acid solutions showed that molecules of humus acids keep radiogenic uranium by one and a half or two times weaker as compared with parent uranium. It points at different character or different quantity of chemical bonds produced by both uranium isotopes.

The conclusions are as follows:

1. The molecules of humus acids destroyed as a result of nuclear disintegration of uranium (and other nuclides) are able to restore their initial structure in the shale organic matter or a structure identical to the initial one. 
2. Radiogenic uranium reacts with functional groups of humus acids in the solid phase forming respective chemical compounds (uranium humates and fulvates).

3. Chemical bonds of radiogenic uranium in the composition of a humate complex are weaker than those of its parental isotope possibly because of different valent state of uranium isotopes.

4. By stability of the bonds of uranium atom with humus acids, the complexes formed at their interaction can be ranged as follows:

- weakest - complexes formed at short-term interaction of uranyl ions with humus acids in the liquid phase;

- relatively strong - compounds formed with participation of radiogenic uranium (VI) in the solid phase of shale organic matter

- strong - humate and fulvate complexes formed with participation of uranyl ion of parental isotope ${ }^{238} \mathrm{U}$ in the solid phase;

- very strong - complexes formed with participation of tetravalent uranium, especially in close association of humin and clay minerals.

\section{ЛИТЕРАТУРА}

1. Стивенсон, Ф. Дж., Батлер, Дж. Х. А. Химия гуминовых кислот и родственных пигментов // Органическая геохимия / Дж. Эглинтон, М. Т. Дж. Мэрфи (ред.). Ленинград, «Недра», 1974. С. 389-412.

2. Idiz, E.F., Carlisle, D., Kaplan, I. R. Interaction between organic matter and trace metals in a uranium rich bog, Kern Country, California, U.S.A. // Appl. Geochem. 1986. Vol. 1. P. 573-590.

3. Koglin, E., Shenk, H. J., Schwochau, K. Spectroscopic studies on the binding of uranium by brown coal // Appl. Spectroscopy. 1978. Vol. 32. P. 486-493.

4. Rao, L., Choppin, G. R., Clark, S. B. A study of metal-humate interactions using cation exchange // Radiochim. Acta. 1994. Vol. 66/67. P. 141-147.

5. Denecke, M. A., Pompe, S., Reich, T., Moll, H., Bubner, N., Heise, K. N., Nicolai, $R$., Nitsche, $H$. Measurements of the structural parameters for the interaction of uranium(VI) with natural and synthetic humic acids using EXAFS // Radiochim. Acta. 1997. Vol. 79. P. 151-159.

6. Салаи, $A$. Роль гумусовых кислот в геохимии урана и их возможная роль в геохимии других катионов // Химия земной коры: Тр. геохимической конференции «Химия земной коры», посвященной столетию со дня рождения В.И. Вернадского. Москва: «Наука», 1964. Т. 2. С. 428-442.

7. Титаева, Н. А., Таскаев, А. И. Миграция тяжелых естественных радионуклидов в условиях гумидной зоны. - Ленинград: «Наука», 1983, с. 10.

8. Ivanovich, M., Wolf, M., Geyer, S., Fritz, P. Isotopic characterization of humic colloids and other organic and inorganic dissolved species in selected groundwaters from sand aquifers at Gorleben, Germany // Humic and Fulvic Acids. American Chemical Society, Washington. 1996. P. 220-243.

9. Bogdanov, R. V., Gerasimov, S. A., Ozernaya, S. A., Pihlak, A. A., Sergeev, A. S. Organic substance as a collector of recoil atoms Th-234 (U-234) in black shales // Czechoslovak J. of Physics. 1999. V. 49, Suppl. S1. P. 65-70. 
10. Bogdanov, R. V., Ozernaya, S. A., Orlova, N. E., Sergeev, A. S., Timofeev, S. A. Organic components labeled with U-238 radioactive decay products in Dictionema shales resulting from nuclear recoil processes // 5th Intern. Conf. on Nuclear and Radiochemistry. Pontresina, Switzerland, September 3-8, 2000. Extended Abstracts. Bern, 2000. Vol. 2. P. 436-439.

11. Богданов, P. В., Озерная, С. А., Сергеев, А. С., Орлова, Н. Е. Радиоактивность органического вещества черных диктионемовых сланцев // 3-я Российская конф. по радиохимии «Радиохимия2000».С.Петербург, 28 ноября - 1 декабря 2000. Тез. докл. С.Петербург, 2000. C. 228.

12. Манская, С. М., Дроздова, Т. В. Геохимия органического вещества. Москва : «Наука», 1964. С. 172-180.

13. Dypvik, H., Bue, B. The U, Th and $\mathrm{K}$ distribution in black shales of the Janusfjellet Formation, Svalbard, Norway // Chem. Geol. 1984. V. 42, No. 1-4. P. 287-296.

14. Богданов, Р. В., Озерная, С. А., Пихлак, А. А., Липпмаа, Э. Т. Изучение поведения атомов отдачи ${ }^{234} \mathrm{Th}\left({ }^{234} \mathrm{U}\right)$ в углеродистых сланцах // Вестник СПбГУ. 1995, Серия 4, № 4. С. 57-61.

15. Аринушкина, E. В. Руководство по химическому анализу почв. 2 изд. Москва : Изд. МГУ, 1970.

16. Пономарева, В. В., Плотникова, Т. А. Методические указания по определению содержания и состава гумуса в почвах. - Ленинград, 1975.

17. Плотникова, Т. А., Пономарева, В. В. Упрощенный вариант метода определения оптической плотности гумусовых веществ с одним светофильтром // Почвоведение. 1967. № 7. С. 73-85.

18. Umemoto, Sh. Determination of ${ }^{234} \mathrm{U} /{ }^{238} \mathrm{U}$ isotopes of uranium in natural materials // Radiochim. Acta. 1967. Vol. 8, No. 2. P. 107-111.

19. Богданов, Р. В., Козак, П. П., Тупищын, И. И. Алгоритм и программа обсчета альфа-спектров для случая трех пиков // Вестник СПбГУ, 1995, cep. 4, № 4. C. 65-71.

20. Богданов, Р. В., Озерная, С. А., Пихлак, А. А., Липпмаа, Э. Т. Межфазовое разделение четных изотопов урана в диктионемовых сланцах Прибалтийского бассейна // Радиохимия. 1996. Т. 38, вып. 4. С. 344-354.

21. Tipping E. Modelling the binding of Europium and the actinides by humic substances // Radiochim. Acta. 1993. Vol. 62. P. 141-152.

22. Bogdanov, R., Lippmaa, E., Ozernaya, S., Pihlak, A. Isotopic abundance of uranium (IV) and uranium (VI) species in leachants of graptolitic argillites // Oil Shale. 1991. Vol. 8, No 2. P. 125-131.

23. Zhang, Y.-J., Bryan, N. D., Livens, F. R., Jones, M. N. Complexing of metal ions by humic substances // Humic and Fulvic Acids. American Chemical Society. Washington. 1996. P. 194-206.

Presented by J. Kann

Received April 17, 2006 